\title{
Identidades e relações de poder nos cristianismos originários: as cartas de Cícero e Paulo em perspectiva comparada
}

\author{
Identities and power relationships in early Christianities: the letters \\ of Cicero and Paul in compared perspective
}

\section{André Leonardo Chevitarese* \\ Daniel Brasil Justi ${ }^{* *}$}

RESUMO

O presente ensaio visa discutir o processo de formação de identidades em contexto de cristianismos originários no interior do mundo romano. Para tanto, cumpre perceber de que forma as interações entre agentes históricos e cultura na qual estavam inseridos moldam os resultados e estratégias de processos comunicativos. Neste ensaio, as cartas de Cícero e Paulo são consideradas como potentes instrumentos que revelam relações de poder e construção de identidades em seus respectivos tempos e espaços

Palavras-chave: Identidades, relações de poder, Paulo, Cícero, cristianismos originários.

\section{ABSTRACT}

This essay discusses the identity formation process in Christianities context originated within the Roman world. Therefore, it must be understood how the interactions between agents and historical culture in which they were inserted shaped the results and communicative processes strategies. In this essay, the letters of Cicero and Paul are regarded as powerful tools that reveal power relationships and identity construction in their respective times and environment.

Keyword: Identities, power relationships, Paul, Cicero, early christianities .

\footnotetext{
* - Doutor em Antropologia Social pela Universidade de São Paulo. Professor Associado do Instituto de História da UFRJ, atuando no Programa de Pós-Graduação em História Comparada.

** - Doutor em História Comparada pela Universidade Federal do Rio de Janeiro. Pós-Doutorando no Museu Nacional UFRJ. Bolsista do Conselho Nacional de Desenvolvimento Científico e Tecnológico - CNPq - Brasil no Programa de Pós-Graduação em Arqueologia.
} 
De imediato convém salientar a partir de que perspectiva de identidade os autores partem para elaborar o presente trabalho. Considerar os estudos de cristianismos antigos, quase invariavelmente, é discutir relações de poder e consolidação de identidades. O motivo é relativamente simples: os cristianismos mediterrânicos entre os séculos I e II EC gradativamente começam a se afastar de sua matriz religiosa judaica originária (embora sempre tenham se visto como judeus) e, cada vez mais, vão se convertendo em outras percepções do que sejam as suas próprias experiências fé.

Nesse processo, as ideias forjadas vão ganhando outros contornos diferentes daqueles originários, mas mantendo com eles relações de pertença-separação. De identificação e estranhamento. De identidade e alteridade. A origem e consolidação dessas ideias, porém, jamais se afastam de seu universo cultural primevo, antes, guardam com ele uma relação de continuidade, ruptura e ressignificação de conceitos, símbolos ou costumes.

Assim, a forma com que os autores entendem o processo de formação de identidades nos cristianismos originários tem a ver com o universo cultural em que se inserem os agentes históricos paleocristãos. A nascente percepção cristã de como devem ser organizadas as bases dessas experiências religiosas estão intrinsecamente conectadas com a matriz cultural em que estão inseridas.

Logo, para se perceber como se comunicam, constroem identidades ou estabelecem relações de poder é imperioso que se observe esses cristianismos originários completamente inseridos nos códigos culturais de seu tempo. A partir daí, então, cruzando as informações de como o "mundo romano" operava os códigos da cultura com a forma com que autores paleocristãos inseriram suas percepções de realidade obter-se-á um retrato mais cotidiano e plausível de como essas identidades se formaram à partir dos dados culturais disponíveis a esses primeiros "cristãos".

Partindo da premissa de que esses autores paleocristãos estavam com seus pés no chão e interagindo intensamente com suas próprias culturas, objetiva-se aqui lançar luz na circulação de correspondências no império romano, através de um aspecto normalmente negligenciado pelos atuais leitores desse tipo de documentação: a diversidade social envolvida no processo de levar e trazer cartas. Quando esse aspecto é acentuado, indícios vêm à tona, como a sugerir novos objetos de pesquisa. Como se trata de um ensaio, ao invés de um artigo pronto e acabado, o mais importante é que ele suscite discussão, pelo menos esse é o desejo dos seus autores.

A fim de analisar o aspecto proposto, dois procedimentos serão adotados: $\left(1^{\circ}\right)$ o uso do corpus ciceroniano conhecido por "Cartas aos seus Amigos"1. Ele é composto de trezentas e trinta e seis correspondências ${ }^{2}$ produzidas entre as décadas de cinquenta e quarenta do século I aEC; e (2º) os resultados advindos desse material serão aplicados a uma pequena carta, quase um bilhete,

\footnotetext{
${ }^{1}$ Daqui em diante, Cartas.

2 O volume I contém oitenta e sete correspondências; o volume II apresenta cento e setenta; o volume III (apenas o livro 13) dispõe de setenta e nove cartas. Portanto, há um total de trezentas e trinta e seis correspondências lidas para a produção desse brevíssimo ensaio.
} 
denominada de "Epístola a Filemon". A sua escolha serve exatamente para testar a viabilidade ou não do que está sendo proposto nesse ensaio.

\section{I.}

A leitura das correspondências de Cícero permite identificar diferentes formas de um indivíduo se manter informado no Império Romano. A carta é apenas uma delas, coexistindo outros meios de informação, como por exemplo: breves mensagens orais (Cícero. Cartas 1.5b:1, 5.11:2); disseminação oral de uma novidade no espaço público (Cícero. Cartas 2.6:1); extensos relatos orais (Cícero. Cartas 3.1:1-2, 3.5:3, 3.7:4, 7.14:1-2, 10.7:1); leitura pública (Cícero. Cartas 10.6:1) ou privada (Cícero. Cartas 9.1.1, 10.12:2, 10.21:3, 10.33:2) de uma correspondência; uma espécie de "jornal" diário ${ }^{3}$ (Cícero. Cartas 12.8:1); "cadernos" contendo anotações militares (Cícero. Cartas 11.11:1); livro de anotação contendo as cópias de cartas enviadas (Cícero. Cartas 9.25:1).

A carta, porém, goza de uma centralidade na forma de comunicação entre indivíduos, principalmente se esses se inserem nas camadas mais altas da sociedade romana. Uma correspondência pode ser (a) redigida pelo próprio remetente ${ }^{4}$, mas, nesse caso, como parece ser raro, o feito é mencionado (Cícero. Cartas 3.6:2, 7.18:1, 9.16:1, 10.21:1,3); ou, o que parece ser o mais comum, (b) ditada a um secretário (Cícero. Cartas 5.20:1,8), possivelmente pertencente às camadas mais baixas da sociedade, podendo ser prioritariamente, mas não exclusivamente, liberto e/ou escravo. Depois que ela é redigida, diferentes agentes sociais, gozando dos mais variados estatutos sociais, tornam-se os responsáveis pela sua entrega ao destinatário (ver Quadros 1, 1a, $1 \mathrm{~b}, 1 \mathrm{c})$.

Quadro 1- Agentes Sociais envolvidos na entrega de Cartas

\begin{tabular}{|c|c|}
\hline Escravo & $4.12: 2,6.20: 1,8.12: 4,9.10: 1,11.11: 1$ \\
\hline Liberto & $2.7: 3,3.1: 1-2,3.7: 4,4.9: 1,4.10: 1,6.18: 1,8.8: 10$ \\
\hline Livre & $\begin{array}{l}\text { 2.6:1, 8.8:10, 9.6:1, 10.7:1, 10.12:2, 10.18:1, 11.5:1, 11.6:1, 10.12:1, } \\
10.25: 1,12.25 a: 1\end{array}$ \\
\hline Não especificado & $\begin{array}{l}\text { 3.10:2, 3.11:1, 9.9:3, 9.15:1, 10.31:1,3, 10.12:1, 10.16:1, 10.21:5, 12.12:1, } \\
\text { 12.22:4 }\end{array}$ \\
\hline
\end{tabular}

\footnotetext{
${ }^{3}$ Acta Diurna. Ele foi publicado, pela primeira vez, no primeiro consulado de César, em 59 aEC. Ele trazia informações sobre as ações do Senado, nascimento e morte, além de outras importantes notícias.

${ }^{4}$ Stowers (1989: 60-61) observa, em outras cartas, o quanto era comum uma mensagem ser escrita por um secretário, excetuando a despedida e o adeus, que poderia ser escrito pelo próprio remetente. Essa prática era equivalente a colocar uma assinatura na carta ditada. Sobre essa questão, há ótimos exemplos também no material epistolário paulino (1Cor 16:21; GI 6:11; Cl 4:18; Fm 19; Rm 16:22).
} 
Quadro 1a- Detalhando a Categoria Escravo

\begin{tabular}{|l|l|}
\hline Escravo (servi) & Servo (pueris) \\
\hline $8.12: 4,9.10: 1$ & $4.12: 2,6.20: 1,11.11: 1$ \\
\hline
\end{tabular}

Quadro 1b- Detalhando a Categoria Livre

\begin{tabular}{|l|l|l|l|}
\hline Amigo & Estrangeiro & Legado & Jovem \\
\hline $\begin{array}{l}2.6: 1, \quad 9.6: 1, \quad 10.7: 1, \quad 10.12: 1, \\
10.12: 2,10.25: 1,11.5: 1,11.6: 1\end{array}$ & $8.8: 10$ & $10.18: 1$ & $12.25 \mathrm{a}: 1$ \\
\hline
\end{tabular}

Quadro 1c- Detalhando o Termo Não Especificado

\begin{tabular}{|l|l|l|}
\hline Agente & Mensageiro & Indeterminado \\
\hline $3.10: 2,3.11: 1$ & $\begin{array}{l}9.9: 3,9.15: 1,10.31: 1,3,10.12: 1,12.12: 1, \\
12.22: 4\end{array}$ & $9.15: 1,10.16: 1,10.21: 5$ \\
\hline
\end{tabular}

Torna-se evidente, dos dados advindos dos quadros anteriores, que dois grupos sociais se destacam no serviço de entrega de correspondências: homens livres (Quadro 1b), a maioria deles, quando especificados, parece ser cidadãos e libertos (Quadro 1). A coluna denominada de "Não Especificado", quando desmembrada (Quadro 1c), parece sugerir uma composição de libertos e escravos, com uma maior probabilidade de esses últimos virem a ser a minoria. Tudo vai depender quem venha a ser definido como mensageiro (tabellarius). No entanto, convém observar, dos grupos sociais especificados no Quadro 1, os escravos (Quadro 1a) gozam da menor participação no serviço de entrega de correspondências. Esse aspecto pode ser explicado, se não no todo, ao menos em parte, pela possibilidade de ele vir a fugir, caso a distância a ser percorrida seja suficientemente longa para colocá-lo fora do alcance do seu senhor. Nesse momento, o escravo é capaz de criar seus próprios estratagemas para garantir a sua fuga (Cícero. Cartas 13.77:2) De qualquer forma, convém salientar, o quanto é amplo o espectro social de indivíduos envolvidos no serviço do levar e trazer cartas: ele vai do cidadão ao escravo, passando por estrangeiros livres, libertos, servos. 
A elite romana, formada por pessoas como Cícero e seus amigos, mantinha, em suas próprias residências (Cícero. Cartas 2.4:1), ou mesmo fora delas (Cícero. Cartas 12.12:1), mensageiros à sua disposição. Esses últimos eram, em alguns casos, pessoas de extrema confiança ${ }^{5}$, as quais gozavam de uma estreita relação de intimidade junto aos seus patronos. Tal relação não está diretamente ligada ao lugar social ocupado por esse portador de correspondências na sociedade romana, mas, ao contrário, ela parece ser mais o resultado de um processo de confiança construído ao longo do tempo do que propriamente uma questão de ordem social. Assim, por exemplo, encontram-se passagens relacionadas a mensageiros, identificados nos textos como sendo libertos, cuja ênfase recai na sua afeição e delicadeza (Cícero. Cartas 3.2:1); na sua sagacidade e no espírito inquisidor, sem, obstante, ser desagradável (Cícero. Cartas 3.1:1-2); na sua capacidade de expressar fielmente o desejo do seu patrono (Cícero. Cartas 3.5:3); na sua lealdade e boa-vontade (Cícero. Cartas 4.9:1); no conhecer os pensamentos mais íntimos do senhor (Cícero. Cartas 6.10a.1); na sua participação em reunião, junto com cidadãos, na casa do senhor (Cícero. Cartas 10.25:3). Chega-se mesmo ao requinte de um nobre, como Cícero (Cartas 10.16:1), preparar e confiar no mensageiro de sua carta, tal como ele expressa em sua correspondência a Décimo Bruto, escrita entre maio ou junho de 43 aEC.

\begin{abstract}
Eu tenho instruído, por conseguinte, a pessoa que eu te enviei (quem ad te misi) a estar atenta ao momento certo para te entregar a carta. Você sabe que, no momento de uma conversa particular, aqueles que se aproximam de nós, nessas horas, são sempre causa de chateação. Da mesma forma, as cartas são causa de ofensa, se entregues inoportunamente. Se, contudo, e eu espero que assim seja, nada esteja te incomodando, nem te chateando, e meu mensageiro tenha sido hábil e discreto o bastante na escolha do momento certo para se aproximar de você, eu estou certo que eu não terei dificuldade em obter de você tudo aquilo que eu desejo.
\end{abstract}

O movimento de ir e vir daqueles que transportam correspondências pelas estradas do império romano não era fácil, nem tranquilo. Eles estavam sujeitos aos mais variados tipos de perigos, com suas vidas ganhando contornos dramáticos, conforme atestam duas cartas. A primeira delas, escrita por Cássio, quando ele se encontrava em um acampamento militar na Síria, no dia 7 de maio de 43 aEC, informa a Cícero (Cartas 12.12:1) de maneira muito breve: "Mas se nenhuma carta tem te alcançado, eu não tenho dúvida que Dolabela [...] prendeu meus mensageiros (tabellarios) e interceptou os meus despachos".

\footnotetext{
${ }^{5}$ Obviamente que isso não se aplicava a todos os casos. Um ótimo exemplo é a reclamação que Célio faz na carta enviada a Cícero. Ele reclama da morosidade do escravo (servi) de Cícero que está levando a sua carta. Ele escreve (Cicero. Cartas 8.12:4): "desde que eu recebi a sua última (carta), ele tem permanecido aqui por mais de quarenta dias".
} 
A segunda delas, escrita por Asínio Pollio, em Córdoba, no dia 16 de março de 43 aEC., torna ainda mais explícito a Cícero (Cartas 10.31:1) os riscos a que estavam sujeitos todos aqueles que se serviam das estradas:

\begin{abstract}
Muito embora seja verdade que o paço de Castulo (saltus Castulonensis), que os nossos mensageiros (tabellarios) sempre utilizam, tem agora se tornado mais perigoso do que antes, devido ao aumento de bandidos, isso não é nada se comparado aos enormes atrasos causados por àqueles que ficam postados em todos os lugares, de ambos os lados (do referido paço), procurando pelos nossos mensageiros (tabellarios), detendo-os.
\end{abstract}

Por isso, em diferentes momentos, a documentação enfatize a necessidade de (a) se enviar carta duplicada (Cícero. Cartas 4.4:1, 9.16:1, 10.5:1, 11.11:1); (b) mandar mais de um mensageiro com cartas cujos conteúdos sejam absolutamente idênticos (Cícero. Cartas 10.33:3); e (c) impor limites ao que se pode escrever em uma carta (Cícero. Cartas 10.20:4, 10.21:5, 11.10:2).

II.

O que esses dados projetam na pequena "Epístola a Filemon"? De imediato, alguns elementos introdutórios precisam ser explicitados: $\left(1^{\circ}\right)$ não é decisivo, para o que se quer aqui abordar, o fato de a referida carta, inserida no corpus paulino, ter sido escrita quase um século depois daquelas trocadas por Cícero com seus amigos; e $\left(2^{\circ}\right)$ também não é central, nesse ensaio, discutir se a "Epístola a Filemon" seria ou não genuinamente de Paulo6.

Essa carta apresenta alguns dados comuns àqueles contidos nas de Cícero, enquanto que outros simplesmente estão ausentes (ver Anexo I). São conhecidos os remetentes, Paulo e Timóteo, e o destinatário, Filemon. Faltam, no entanto, elementos que ajudem o leitor a determinar (a) a geografia da sua origem e do seu destino ${ }^{7}$, bem como (b) a sua datação ${ }^{8}$.

\footnotetext{
${ }^{6}$ Koester (1987, p. 134) parece não ter nenhuma dúvida de que se trata mesmo de uma carta paulina; Fitzmyer (2008, p. 8-9) coloca o leitor a par dos prós e contras de a autoria da carta ser de Paulo. No entanto, ele deixa claro que "hoje a autenticidade [paulina] da Carta de Filemon é quase universalmente aceita".

7 Koester (1987, p. 135) acompanha acriticamente o argumento que o destinatário aqui citado seja o mesmo mencionado em Cl $(4: 9,17)$. Nesse caso, segundo o referido autor, Filemon, depois de ter sido batizado por Paulo em Éfeso, teria se mudado para Colossos. Ele estaria morando lá enquanto líder e fundador da igreja naquela cidade. Paulo, preso em Éfeso, teria enviado a carta dessa última localidade. Assumindo corretamente uma posição mais
} 
Não deixa de ser curioso observar como oscila rapidamente a autoria da carta; ela passa de dois autores (Fm 1) - "Paulo, prisioneiro de Cristo Jesus, e o irmão Timóteo, a Filemon [...]" - para somente um (Fm 4) - "Dou sempre graças ao meu Deus [...]". A pessoa de nome Timóteo, citada uma única vez na carta, poderia (a) até estar junto de Paulo; (b) ser conhecida pelo remetente e destinatário; e (c) ser reconhecida por ambos como autoridade para respaldar o conteúdo da carta (FITZMYER, 2008, p. 85). Mesmo sendo citado meteoricamente, Timóteo parece gozar de uma primazia, talvez, quiçá, ocupando mesmo uma posição hierarquicamente acima da dos demais indivíduos listados na carta, a começar por Epafras, dito ser um companheiro de prisão de Paulo (Fm 23: "Saudações de Epafras, meu companheiro de prisão em Cristo Jesus"), ou Marcos, Aristarco, Demas e Lucas, classificados como colaboradores (Fm 24: "de Marcos, Aristarco, Demas e Lucas, meus colaboradores") do autor.

Paulo é uma autoridade na vida da comunidade instalada na casa de Filemon. Ele não apenas conhece, como é capaz de citar nominalmente outras pessoas que ali congregam ( $F m$ 2: "à nossa irmã Ápia, ao nosso companheiro de armas Arquipo, e à Igreja que se reúne na tua casa."), como é o caso de Ápia e Arquipo, que junto com Filemon, mas não abaixo dele, deveriam ser lideranças locais. O fato de Paulo nomeá-los parece também sugerir que eles também tomariam contato com a carta ${ }^{9}$. Essa sugestão encontra respaldo nas correspondências de Cícero. Na primeira delas, datada de 11 de abril de 43 aEC., e que foi endereçada a Planco, ele (Cícero. Cartas 10.12:2) observa: "Um pouco mais tarde, Munácio também me deu para ler a carta privada que você enviou para ele, como também o despacho público".

Na segunda, datada do início do ano 46 aEC, Cícero (Cartas 9.1:1) fala a M. Terêncio Varro: "[...] eu me perguntei da carta que você enviou para Ático e que ele leu para mim".

Além disso, a autoridade de Paulo é explicitada em outros três momentos, em particular, quando ele emprega palavras que reforçam hierarquias. Na primeira delas (Fm 8-9), ele diz a Filemon: "Por isso, tendo embora toda a liberdade em Cristo para te ordenar o que convém, prefiro pedir por amor".

A seguir, Paulo tem a certeza de que a sua vontade será acatada (Fm 21): "Eu te escrevo certo da sua obediência [...]". Por fim, ele ainda determina ao destinatário (Fm 22): "[...] prepara-me também um alojamento [...]".

crítica, Fitzmyer (2008, p. 9-11, 16), que até gostaria de aceitar o argumento de Koester, já que ele resolveria algumas questões centrais, não apenas admite que a Epístola aos Colossenses é uma carta deuteropaulina, escrita uns quinze anos depois daquela de Filemon, como também reconhece que não é possível determinar o local da prisão de Paulo. ${ }^{8}$ Koester (1987, p. 131) data essa carta do inverno do ano 54-55. Fitzmyer (2008, p. 10), uma vez mais, mostra um melhor compreensão do problema do que Koester, deixando claro que tudo vai depender do lugar onde Paulo se encontrava preso: se em Roma, Cesareia Marítima ou Éfeso. Para cada uma dessas localizações, há uma datação específica. Como não há como saber onde a exata localização da prisão, não há também como precisar uma data para a carta.

${ }_{9}^{9}$ Fitzmyer $(2008$, p. 81) vai mais longe, argumentando que essa era uma carta que seria lida em voz alta para toda a comunidade reunida na casa de Filemon. 
Apesar de essas três passagens se inserirem muito bem no contexto imperial romano, elas não ganham destaque nas cartas de Cícero. Essa ausência se deve, principalmente, ao fato de os interlocutores do referido político serem homens que ocupam altas posições na esfera sócio-política e econômica de Roma. Implica, dizer, as relações se estabelecem mais no plano da horizontalidade do que no da verticalidade, tal como explicitado nas três passagens paulinas ${ }^{10}$. Em Cícero (Cartas 13.3:1, 13.5:1), a horizontalidade das relações demandam outros tipos de tratamento ${ }^{11}$, tal como pode ser observado na correspondência enviada por ele a Caio Memmio: "Eu ficaria feliz se você tratasse dele (A. Fúfio), conforme você me prometeu fazer, quando nós nos encontramos".

Ou como ainda pode ser lida em outra carta endereçada a Valério Orca no outono do ano 45 aEC. "[...] eu estou cercado por petições de um grande número de homens, porque eles confidentemente clamam pela sua boa-vontade, através de mim".

Filemon é descrito como um amado colaborador do autor da carta (Fm 1: "Paulo, prisioneiro de Cristo Jesus, e o irmão Timóteo, a Filemon, nosso muito amado colaborador,"). Há bons indícios, nesse documento, que ajudam o leitor a defini-lo com alguma segurança. De imediato, ele parece ser um homem letrado, na medida em que houve uma clara opção, da parte de Paulo, em Ihe escrever uma carta. O seu papel de liderança na igreja não se deve apenas à expertise em questões religiosas ou a sua fé em Cristo Jesus, mas, por ele ser um homem de posses. A comunidade se reúne na sua casa (Fm 2: "à nossa irmã Ápia, ao nosso companheiro de armas Arquipo, e à Igreja que se reúne na tua casa"). Para isso, ela deve dispor de um espaço, móveis e utensílios, permanentes ou provisórios, para abrigar, por algumas horas, em determinados dias da semana, fiéis internos e externos à casa, além de outras possíveis pessoas convidadas a participar do culto. Agrega-se aí o fato de a sua residência dispor de outros cômodos, além daqueles utilizados cotidianamente, já que Paulo pede a Filemon que o aloje ali (Fm 22: "Ao mesmo tempo, prepara-me também um alojamento, porque, graças às vossas orações, espero que vos serei restituído"). Tudo concorre para se pensar Filemon como sendo um homem rico, pois além de ele ser proprietário de escravos e a sua casa ter um tamanho considerável, ela ainda é dotada de bens de valor (FITZMYER, 2008, p. 13), dentre os quais, alguns deles foram furtados pelo seu escravo Onésimo, quando esse optou por fugir (Fm 18: "E se ele te deu algum prejuízo ou te deve alguma coisa, põe isso na minha conta") ${ }^{12}$.

Dois aspectos merecem aqui ser sublinhados. O primeiro deles tem a ver com o fato de a casa de Filemon ser dotada de mais cômodos do que aqueles necessários para acomodar os seus próprios familiares, incluindo aí os escravos. Encontra-se em uma correspondência escrita a G.

\footnotetext{
${ }^{10}$ Koester (1987, p. 135) estranhamente ignora esses passos, deixando claro que Paulo não emprega sua autoridade apostólica e deixa toda a decisão para Filemon.

${ }_{11}$ Para outros exemplos, ver: Cícero. Cartas 13.1:6, 13.3:1, 13.4:3-4, 13.5:1.

12 Williams (2007, p. 175, nota 27) parece sugerir, em oposição à leitura de Onésimo como sendo um escravo fugitivo, que o próprio Filemon o enviou em socorro a Paulo, enquanto esse último era um prisioneiro, tal como ocorre com Epafródito (cf. Fl 2:25-30). A proposta é interessante, porém, Epafródito é apresentado como leitourgós. O desempenho de uma leitourgía não apenas nessa passagem, como também em outras, não é própria para um escravo; para uma discussão mais detalhada sobre Onésimo ter mesmo fugido. (HORSLEY, 2007, p. 55-60; HORSLEY, 1998, p. 40-46).
} 
Memmio por Cícero (Cartas 13.2:1), quando ele se achava em Laodiceia, em maio do ano 50 aEC, um pedido que apresenta paralelo com aquele feito por Paulo a Filemon:

Eu sou próximo de C. Aviano Evandro, que está hospedado na capela (sacrario) de sua família, e muito mais próximo ainda do patrono dele, M. Emílio. Eu the peço, com mais ênfase do que o normal, portanto, [...] para acomodá-lo em sua residência. [...] você me terá feito um enorme favor.

Ninguém faz um pedido como esse de Cícero, sem admitir, a priori, que o seu destinatário possua uma casa suficientemente grande para poder abrigar mais uma pessoa (no caso, em questão, um liberto), sem que isso venha a interferir (a) na sua privacidade, (b) na sua capacidade de movimento no interior de sua residência e (c) na rotina diária de sua família. Esse parece ser o caso de Paulo (Fm 22: "Ao mesmo tempo, prepara-me também um alojamento, porque, graças às vossas orações, espero que vos serei restituído"), quando demandou de Filemon um alojamento.

O segundo aspecto a ser considerado diz respeito ao fato de Onésimo, o escravo de Filemon, no momento em que fugiu, ter furtado bens da casa do seu senhor (KOESTER, 1987, p. 135; STOWERS, 1989, p. 155). Em uma correspondência, escrita por Cícero (Cartas 13.77:2), em Roma, no outono do ano 46 aEC, para P. Sulpício Rufo, ele faz um pedido:

Há isso também; eu te imploro com mais força do que o normal, em nome de nossa amizade e de sua devoção invariável para comigo, dar uma atenção mais cuidadosa à seguinte questão: meu escravo Dionísio, que tinha a incumbência da minha custosa biblioteca, tendo roubado um punhado de livros, e achando que ele seria punido pelo roubo, fugiu. Ele está em sua província. Tanto meu amigo Bolano e alguns outros o viram em Narona (costa da llíria), mas quando ele declarou que eu tinha lhe dado a sua liberdade, eles aceitaram a palavra. Se você se encarregar com dessa questão de pegá-lo e devolvê-lo para mim, eu não posso te dizer o quão prazeroso eu ficarei.

Não deixa de ser interessante observar alguns paralelos entre esses dois escravos (ver Quadro 2). 
Quadro 2- Paralelos entre Dionísio e Onésimo

\begin{tabular}{|l|l|l|l|}
\hline Dionísio & Passo & Onésimo & Passo \\
\hline Roubou livros & $13.77: 2$ & $\begin{array}{l}\text { Roubou bens não } \\
\text { ecificados }\end{array}$ & Fm 18 \\
\hline Sabia dos riscos da fuga & $13.77: 2$ & Sabia dos riscos da fuga & Fm 11, 15 \\
\hline Obteve êxito na sua fuga & $5.10 a: 1$ & Obteve êxito na fuga ${ }^{13}$ & Fm 10 \\
\hline
\end{tabular}

1․ Dionísio e Onésimo pertenciam a senhores que possuíam em suas casas bens materiais valiosos. Eles furtaram alguns deles como forma de obterem recursos para fugir - o escravo de Cícero furta livros, como forma de fazer as provisões necessárias para o plano de fuga dar certo; o escravo de Filemon rouba bens que não são especificados, certamente para que eles pudessem ser vendidos durante a fuga;

2ํ․ Dionísio e Onésimo deveriam conhecer muito bem as consequências dos seus atos: casos eles fossem pegos, eles seriam presos e devolvidos aos seus donos. Apesar dos riscos, eles entenderam que valeria a pena tentar fugir.

3‥ No caso de Dionísio, além do trecho citado, há outras passagens, contidas em três correspondências, que projetam um pouco mais de luz no processo relacionado à fuga de escravos no império romano. Ele passa pela troca de informações entre os proprietários de escravos, chegando até o uso de aparato militar para tentar recapturá-los. As cartas contendo as informações sobre Dionísio cobrem um período de quase dois anos. A primeira delas foi escrita por Públio Vatínio, do acampamento militar em Narona ${ }^{14}$, no dia 11 de julho de 45 aEC. Ele diz a Cícero (Cartas 5.9:2):

Eles me disseram que seu escravo (Dionísio), seu leitor, que fugiu, juntou-se aos Vardaei; você não me disse nada sobre isso, mas, eu dei uma autorização provisória para que ele seja perseguido por terra e mar, e eu estou convencido de que o encontrarei para você, salvo se ele tiver escapado para a Dalmácia.

\footnotetext{
${ }^{13}$ Não deixa de ser interessante a observação feita por Williams (2007, p. 60) de que Paulo, ao assumir para Filemon que Onésimo é "seu filho gerado na prisão", toma para si a total responsabilidade pelos atos praticados pelo seu "filho". Isso explicaria, de forma satisfatória, o argumento de Paulo de que se o seu "filho" Onésimo tivesse dado algum prejuízo ou estava em débito com Filemon (cf. Fm 10,18), que essa dívida seria saldada pelo próprio apóstolo.

${ }^{14}$ Cidade situada na costa da llíria.
} 
O sujeito "eles", da carta, se refere aos amigos de Cícero que pedem a Vatínio ajuda para recapturar o escravo. Na passagem, esse comandante militar parece reclamar com Cícero sobre o porquê de ele não o ter informado antes. Mas, apesar disso, ele se prontifica a utilizar todos os meios disponíveis para conseguir prender Dionísio.

Em resposta, Cícero (Cartas 5.11:2), escrevendo de Roma no final de outubro de 45 aEC, pede pressa à Vatínio na prisão de seu escravo. A passagem deixa transparecer a existência de um processo de negociação envolvendo Vatínio e Dionísio. Cícero, porém, deixa claro que não está disposto a arcar com nenhum custo para obter o seu escravo fugitivo.

Sobre Dionísio, como você é meu amigo, termine essa questão; qualquer que tenha sido a promessa que você lhe fez, eu devo recebê-lo livre de pagamento. Se, porém, ele se mostrar mau-caráter (como de fato ele é), você o trará cativo em seu triunfo.

Por fim, apesar de todos os esforços e meios utilizados, Públio Vatínio, ao escrever para Cícero (Cartas 5.10a:1) de Narona, no final de janeiro de 44 aEC., se vê forçado a reconhecer ao amigo que: "Apesar das minhas buscas, eu não tenho nenhuma informação acerca do seu Dionísio [...]. Eu não vou descansar, porém, até pegá-lo de uma maneira ou de outra".

Até onde os dados nos permitem acompanhar, a última fala de Vatínio ficou mesmo na promessa. Dionísio logrou êxito no seu plano de fuga e não foi recapturado.

Onésimo parece ter contado com a mesma sorte daquela de Dionísio ${ }^{15}$. Ele não foi capturado, conseguindo, assim, chegar até onde Paulo se encontrava preso - custodia libera ${ }^{16}$. Possivelmente esse seu encontro com o referido apóstolo teria sido o resultado de algo previamente planejado, pois Onésimo parecia saber do enorme prestígio exercido por Paulo sobre Filemon - algo do tipo amicus domini. Lá, ele se aproxima do apóstolo, ganha a sua confiança, e the pede ajuda, a fim de resolver alguma pendência junto a Filemon, o seu senhor.

Pode-se especular que o local da prisão domiciliar de Paulo não deveria ser muito distante do lugar no qual morava Filemon, mas não tão perto o bastante para que esse último pudesse ser rapidamente alcançado por algum dos mensageiros do autor da carta. Por conseguinte, o contato entre Onésimo e Paulo deve ter durado o tempo suficiente para Filemon (a) ser informado que o seu escravo estava com Paulo; e (b) enviar um agente seu até lá para reaver a sua propriedade. É

\footnotetext{
${ }^{15}$ Caso Onésimo tivesse sido capturado, ele teria sido confinado em uma prisão própria para escravos - ergastulum (SÊNECA, 1928, p. 32, [Sobre a Ira]; FITZMYER, 2008, p. 13).

${ }^{16}$ Alguma coisa parecida com a prisão domiciliar, tal como mencionada em At 28:16,30 (FITZMYER, 2008, p. 13).
} 
nesse intervalo de tempo que Onésimo se converte ao movimento de Jesus (FITZMYER, 2008, p. 14).

Sem forçar por demais a epístola, é possível sugerir também que ao retornar a Filemon, Paulo tenha incumbido o próprio Onésimo de ser o mensageiro da própria carta ao seu senhor ${ }^{17}$ (FITZMYER, 2008, p. 24; HORSLEY, 2007, p. 59). Neste caso, (a) Onésimo acreditava que a carta de Paulo, cujo conteúdo ele próprio deveria conhecer, seria capaz de demover Filemon de lhe aplicar qualquer castigo, inclusive o físico; e (b) a decisão final quanto ao seu destino ficaria nas mãos de Filemon.

É plenamente plausível o argumento de que Onésimo esperasse que determinadas palavras de Paulo viessem aplacar a fúria de Filemon, tais como: "ele é como se fosse meu próprio coração" (Fm 12); ou "talvez ele tenha sido retirado de ti por um pouco de tempo, a fim de que o recuperasses para sempre, não mais como escravo, mas, bem melhor do que como escravo, como um irmão amado" (Fm 15-16); ou ainda "portanto, se me consideras teu amigo, recebe-o como se fosse a mim mesmo" (Fm 17) ${ }^{18}$. Um reforço de peso nesse processo de sensibilização era o fato de que tais palavras vinham endossadas por um homem como Timóteo, pelo companheiro de prisão Epafras, e pelos colaboradores Marcos, Aristarco, Demas e Lucas.

Mas as palavras de Paulo não devem ser tomadas como ordens absolutamente cumpridas à risca, sem questionamento, por parte de quem as lê. Implica dizer que não deve ser assumido categoricamente que Filemon, após a leitura da carta, tenha alforriado Onésimo. Ele poderia continuar perfeitamente como escravo, passando a gozar de uma situação diferenciada, se comparada com outros escravos, conforme observa Cícero (Cartas 7.20:1), da cidade de Velia, a C. Trebatio Testa, no dia 20 de julho do ano 44 aEC: "[...] mesmo o seu homem Rúfio (escravo arquiteto de Trebatio) é tão sentida a ausência dele aqui, como se ele fosse um de nós".

Onésimo poderia se tornar um escravo como Rúfio, tão perfeitamente adaptado à sua condição de escravo, demonstrando tamanha segurança ao seu senhor e aos amigos dele, que a sua ausência passa a ser sentida.

Possivelmente a sua nova fé, projetando-Ihe a esperança de uma segunda vinda imediata de Jesus ou a sua acolhida em breve na Jerusalém Celestial, o tivesse transformado em um escravo diferente do que ele era, fazendo-o abrir mão de táticas pouco valorizadas pelos senhores, tal como observada por Célio (Cartas 8.12:4) a Cícero por volta de 20 de setembro do ano 50 aEC. "Eu estou muito preocupado pela morosidade do escravo (servi) que está levando a sua carta; desde que eu recebi a sua última (carta) ele tem permanecido aqui por mais de quarenta dias".

\footnotetext{
${ }^{17}$ Conforme observado, apesar de o escravo não ser comumente utilizado nesse tipo de atividade (ver Tabelas 1 e 1a) pelas possibilidades reais de ele vir a fugir, esperava-se que o "estágio" com Paulo fosse suficiente para tranquilizar e dar garantias a Onésimo de que valeria a pena retornar à casa do seu senhor.

${ }^{18}$ Stowers (1989: 157) apresenta uma carta escrita em latim por Aurélio Arquelau (Aurelius Archelaus) a um tribuno romano de nome Júlio Domício (Julius Domitius). Nela, o remetente recomenda-lhe um amigo, de nome Theon. Arquelau pede ao tribuno: "[...] olhe para ele como se estivesse olhando para mim".
} 
Essa nova fé abraçada por Onésimo poderia tê-lo feito igual a alguns dos serviçais que trabalhavam para Marcello, que havia sido assassinado por um amigo em casa, que ao invés de fugirem com medo de represálias, permaneceram firmes na residência do senhor, convencidos de que nada Ihes aconteceria, conforme Sérvio Sulpício (Cartas 4.12:2-3), escrevendo para Cícero de Atenas, no dia 31 de maio de 45 aEC, observou:

\footnotetext{
Eu não estava longe do Pireu, quando o servo (puer) de Alcino me encontrou, trazendo-me um bilhete (scriptum) em que afirmava que Marcello tinha morrido um pouco antes da aurora. [...] preocupado, fui até a sua residência (tabernaculum); e lá eu encontrei dois libertos e talvez um ou dois escravos; eles me disseram que os outros haviam fugido em pânico de apreensão, porque, como eles arguiram, seu senhor (dominus) tinha sido assassinado em frente de sua própria residência (tabernaculum).
}

III.

Deve-se ter muita cautela no querer generalizar a Epístola a Filemon, tomando-a prova decisiva de que Paulo (a) visse como uma contradição insuperável um indivíduo ser cristão e, ao mesmo tempo, ser proprietário de escravos, e (b) tivesse colocado em questão a existência da própria instituição escravista. Essas duas generalizações são equivocadas, como também ultrapassam em muito o escopo da referida epístola.

Se as advertências acima devem estar na mente do leitor do documento paulino, bem como na leitura do presente texto, de igual forma, outra importante advertência deve ser atentada, qual seja, a de que o apóstolo operava suas ideias e práticas de forma muito semelhante ao corrente no mundo romano. Tanto para uso de cartas na forma de comunicação, quanto para o conteúdo do que é discutido nesses documentos, o autor revela-se completamente inserido e interagindo com a matriz cultural de seu tempo.

Diante disso, não é difícil projetar nessa carta paulina outro aspecto cultural amplamente disseminado no período romano que diz respeito às relações interpessoais, a saber, a patronagem. Adotar esse conceito, de alguma maneira, contribui para a contextualização das relações presentes entre Paulo redigir uma carta e Filemon recebê-la. Por definição, a patronagem envolve três importantes aspectos: (a) troca recíproca de benefícios (mercadorias e serviços); (b) é pessoal e envolve alguma duração temporal; (c) é assimétrica, no sentido em que as duas partes apresentam estatuto (social, político, jurídico, econômico) desigual, oferecendo tipos diferentes de benefícios (mercadorias e serviços de troca). 
Embora esse último item (c) coloque a patronagem afastada de relações de amizade entre iguais, para o que se quer evidenciar neste ensaio ela não se aplica com propriedade, pois é bastante reconhecido e aceito que a teologia empenhada pelo apóstolo Paulo implica em relações de maior igualdade. Por outro lado, é justamente por meio desse conceito que se torna possível colocar em xeque essa perspectiva. Ora, se o princípio paulino de igualdade entre todos por meio de Jesus extingue as hierarquias e assimetrias, no caso específico aqui abordado é justamente o prestígio de Paulo que desponta como decisivo em sua intervenção a favor de Onésimo.

A contradição, portanto, está evidenciada entre um discurso paulino de igualdade radical e sua posição hierarquicamente superior no caso aqui abordado. Esse, inclusive, é tema de debate entre intelectuais que buscam datação precisa para o documento de Filemon (ver nota 7 acima). Para além da superação da contradição, cabe aqui esboçar que relações interpessoais estavam em jogo entre Paulo e Filemon. O mais interessante desse debate é não se ter disponível o desdobramento do episódio, ou seja, se Filemon, de fato, acolheu Onésimo conforme o pedido de Paulo. Torna-se, portanto, central, o fato de que Paulo lança mão desse recurso para dirimir a querela.

Faz-se necessário evitar a adoção de uma visão mecanicista da patronagem, imaginando que ela fosse um sistema operando regularmente, segundo normas previsíveis e inevitáveis. Os exemplos para isso já foram citados anteriormente, inclusive, para o caso de haver a possibilidade da não aplicação da pena de castigo ou prisão para um escravo fugitivo. Justamente por ser um sistema de relações interpessoais, e estas estarem mediadas pelas contingências específicas de cada caso, a patronagem não precisa ser vista como algo determinista em suas causas e efeitos. Paulo pode ter sido atendido, assim como o contrário também pode ter sido verdadeiro.

O caráter de controle social (relações de poder) da patronagem era apenas mais um de muitos métodos vigentes no interior do Império Romano que dialogava com outros sistemas, como o religioso, por exemplo. É exatamente a configuração de autoridade/submissão presente em sistemas religiosos que permitia uma leitura diferenciada em casos como o de Onésimo. Não há como julgar - porque os elementos da carta não os mencionam - que parâmetros fizeram com que Onésimo fosse orientado a voltar ao seu senhor.

No entanto, certamente, o conhecimento e proeminência de Paulo sobre Filemon (e sua casa enquanto sede de uma comunidade de fé) acabou por ser elemento decisivo nas relações entre as três personagens. Se tomado como verdadeiro que os patronos eram capazes, por causa de suas ligações com o sistema central de poder, de agir como mediadores entre (a) os espaços urbano e rural; (b) entre município e Estado, suas ações gerariam os meios necessários para a obtenção de diferentes recursos. Logo, os clientes nada podiam fazer sem seus patronos.

Obviamente que o caso aqui se desloca: relações políticas (tratando-se de vida política pública) passam a ser relações interpessoais (Paulo - Filemon, Onésimo) e recursos diversos (vida coletiva administrada por governantes) passam a ser obtenção de perdão e/ou acolhimento de um fugitivo em flagrante delito (Onésimo em relação a Filemon, mediado por Paulo). Convertido, portanto, o 
cenário da vida pública para aquela privada, observa-se que Paulo desempenha um papel de patrono em relação a Onésimo, pois garante a ele os recursos desejados e junto a Filemon, pois apela para a autoridade e relação de amizade no acolhimento de Onésimo.

Em todo esse cenário, claramente, não deve ser perdido de vista o elemento comum: Paulo foi o portador da mensagem de Jesus tanto a Onésimo como para Filemon. Assim, a mensagem de Paulo que provocou adesão à promessa de um futuro (físico ou metafísico) de valor ganha status de autoridade. O poder do patrono (Paulo) deriva não da sua habilidade em assegurar benefícios para todos os que o procuram, mas, justamente ao contrário, da sua completa possibilidade de assegurálos para alguns. Torna-se, portanto, mais decisivo para o patrono conhecer e/ou controlar as rotas de acesso aos benefícios desejados do que propriamente possuir uma abundância deles. Isto implica dizer que o segredo da relação patrono/cliente é a manipulação dos recursos e/ou benefícios.

$\mathrm{Na}$ medida em que não se adota aqui o critério teológico de revelação proposicional direta divina na redação dessa carta, mas percebe-se um autor repleto do divino, porém com os seus pés no chão e como um competente decodificador de códigos culturais de seu tempo, o processo de formação de identidade aparece como o elo entre o que os sujeitos vivenciam em suas experiências cotidianas e a maneira com quem vivenciam suas experiências de fé assentadas em bases plurais.

Torna-se desnecessário pressupor ou mesmo discutir se Paulo "copia" o estilo de Cícero. Ou ainda, se o apóstolo tem por objetivo ser um propagandista ou apologista da fé cristã. O que se deve colocar em relevo aqui é a herança cultural compartilhada entre as diferentes regiões mediterrânicas nesse mundo romano e, por conseguinte, os meios disponíveis que seus agentes dispunham para suas intervenções sociais - construções de identidades aqui, em especial - pois, para o que se objetiva nessa relação do documento paulino com seus interlocutores, o que foi organizado enquanto estratégia comunicativa era o que se tinha de disponível naquela realidade cultural, a saber, as epístolas.

\section{Referências}

BÍBLIA. Português. Bíblia de Jerusalém. Nova edição, rev. São Paulo: Paulus, 2002.

BOVER, José M.; O'CALLAGHAN, José (Ed.). Nuevo Testamento Trilingüe. 2. ed. Madrid: La Editorial Católica, 1988. (Biblioteca de Autores Cristianos).

CICERO. The Letters to His Friends. Tradução de W. Glynn Williams. London: Harvard University Press, 1958. v. 1. 
CICERO. The Letters to His Friends. Tradução de W. Glynn Williams. London: Harvard University Press, 1959. v. 2.

CICERO. The Letters to His Friends. Tradução de W. Glynn Williams. London: Harvard University Press, 1979. v. 3.

FITZMYER, J. A. The Letter to Philemon. Tradução e comentários e notas de J. A. Fitzmyer. New Haven: Yale University Press, 2008. (The Anchor Yale Bible).

HORSLEY, G. H. R. New Documents Illustrating Early Christianity. Michigan: Wm. B. Eerdmans, The Ancient History Documentary Research Center, 2007. v. 6.

HORSLEY, G. H. R. New Documents Illustrating Early Christianity. Michigan: Wm. B. Eerdmans, The Ancient History Documentary Research Center, 1998. v. 8

KOESTER, Helmut. Introdução ao Novo Testamento. São Paulo: Paulus, 1987. 2 v.

PLINY. Letters. Tradução de William Melmoth. London: William Heinemann and Harvard University Press, 1958. v. 2

SENECA. Moral Essays. Tradução de John W. Basore. London: William Heinemann and Harvard University Press, 1928. v. 1.

STOWERS, S. K. Letter Writing in Greco-Roman Antiquity. Philadelphia: The Westminster Press, 1989.

WILlIAMS, D. J. Paul's Metaphors. Their Context and Character. $4^{\text {th }}$ ed. Peabody, Massachusetts: Hendrickson, 2007. 


\section{ANEXOS}

Optou-se aqui por trazer ao leitor um debate historiográfico adicional a fim de ampliar as discussões assumidas no corpo do texto e a tradução da Carta a Filemon. A íntegra da carta paulina cumpre o papel de trazer na inteireza a argumentação paulina, posta em diálogo com o corpus documental ciceroniano. Esse procedimento visa conferir destaque ao documento tendo em vista que apenas trechos de seu conteúdo foram selecionados no corpo do texto.

Para o caso das cartas de Cícero, além do óbvio, ou seja, não ser possível transcrever um corpus bastante grande, mas apenas trechos importantes para as discussões aqui apresentadas, 0 que aparece a seguir constitui-se em um interessante ponto de inflexão analítico na historiografia atual, qual seja, a busca por uma interpretação consistente do documento paulino em diálogo com o material ciceroniano.

Portanto, o anexo II se trata, não somente de um elemento de consulta, mas uma leitura integral relevante para a proposta deste ensaio. O primeiro anexo, por sua vez, lança luz a mais um debate historiográfico para além das conclusões assumidas pelos autores deste ensaio.

\section{I.}

Stowers (1989: 155) classifica a epístola de Paulo a Filemon como sendo um texto de intercessão. Partindo dessa premissa, ele cita (Stowers, 1989: 156-165) algumas cartas, advindas de outros contextos históricos, entre as quais aquelas escritas por Plínio, o Jovem (9:21; 9:24). Na primeira (9:21), ele pede a Sabiniano, seu interlocutor, que receba de volta um liberto (libertus) fugitivo. Stowers (1989: 160) diz que esse texto tem sido muitas vezes comparado à referida carta paulina. Na outra carta (9:24) enviada posteriormente, Plínio, o Jovem, parabeniza Sabiniano por ele ter aceito a sua sugestão em relação ao liberto. Essa segunda carta pode ser um interessante meio para se entender a epístola deuteropaulina "Colossenses". O seu autor, que conhecia a "Epístola a Filemon", mostra aos fiéis que o pedido de Paulo foi aceito por Filemon, já que Onésimo (Cl 4:9) aparece trabalhando como missionário da igreja cristã.

Koester (1987, p. 135) aponta uma posição radicalmente oposta àquela acima esboçada, deixando claro que o argumento de Plínio reside no apelo feito à magnanimidade do seu amigo Sabiniano, pedindo-o para perdoar o liberto fugitivo. Em contraste, segundo Koester, a carta a 
Filemon não faz nenhuma menção ao perdão e é meticulosamente pensada, a fim de não colocar Onésimo em uma situação que o amarraria, daquele dia em diante, em gratidão à magnanimidade do seu senhor. Em outras palavras, para Koester, a proposta subliminar de manumissão proposta por Paulo não deveria tornar Onésimo um cliente de Filemon ${ }^{19}$.

Seguem, abaixo, as cartas de Plínio traduzidas para o português, de modo que o próprio leitor possa tirar as suas conclusões.

\section{l.1.}

\section{Carta de Plínio a Sabiniano (9:21 - a datação é incerta).}

Seu liberto, que você disse estar furioso, está comigo; ele se lançou aos meus pés e se apegou a mim com tanta submissão quanto ele poderia ter feito com você. Ele me pediu fervorosamente com muitas lágrimas, e mesmo com toda eloquência de tristeza silenciosa, para interceder por ele; em resumo, ele me convenceu, por todo o seu comportamento, que se arrepende sinceramente de sua falta. E eu estou persuadido que ele está completamente mudado, porque ele sabe que está errado.

Eu sei que você está furioso com ele, e eu sei também que não é sem razão; mas o perdão nunca é mais digno de se pedir do que quando há uma causa justa para o aborrecimento. Você amou esse homem uma vez, e espero que você volte novamente a amá-lo: entretanto, deixe-me somente te persuadir a perdoá-lo. Se daqui em diante ele te for causa de desgosto, você terá muito mais razão para a sua raiva, como você se mostra desejoso para perdoá-lo agora. Permita alguma coisa à juventude dele, às lágrimas dele e à sua própria disposição delicada: não o faça pesaroso por mais tempo, e acrescento também: não faça isso contigo, pois um homem como você, com bondade no coração, não pode sentir raiva, sem sentir uma grande inquietação.

Temo que se eu adicionar o meu pedido ao dele, eu parecesse estar lhe coagindo ao invés de pedir-Ihe que o perdoasse. No entanto, vou fazê-lo e nos termos mais fortes desde que eu o repreendi de maneira muito forte e severa, alertando-o que não vou mais interceder por ele novamente. Embora fosse apropriado dizer isso a ele, a fim de assustá-lo, não era intenção que você ouvisse. Eu posso eventualmente ter a oportunidade de novamente interceder por ele e obter o seu perdão, se o erro for apropriado à minha intercessão e ao seu perdão.

${ }^{19}$ Para uma posição que também enfatiza as diferenças de propósitos entre as referidas cartas de Plínio e aquela de Paulo, ver: NDIEC 8 (1998): 41-42. 


\section{I.2.}

\section{Carta de Plínio a Sabiniano (9:24 - a datação é incerta).}

Aprovo por completo a sua atitude, conforme sugestão da minha carta (9:21), em receber novamente na sua família e no seu favor, um liberto, a quem você uma vez admitiu compartilhar de sua afeição. Isso Ihe dará, não tenho dúvidas, uma enorme satisfação. Certamente, pelo menos para mim, isto é uma prova de que você é capaz de ser governado em sua raiva, como é um exemplo de que você me considera bastante, tanto por obedecer à minha autoridade, quanto por se render à minha súplica. Que você receba, portanto, de uma só vez, o meu aplauso e os meus agradecimentos. Ao mesmo tempo, devo aconselhá-lo, no futuro, a ser brando para com os servos que erram, embora não deva haver ninguém para intervir em seu nome. Adeus.

\section{Anexo II}

\section{Carta de Paulo a Filemon (tradução da Bíblia de Jerusalém).}

${ }^{1}$ Paulo, prisioneiro de Cristo Jesus, e o irmão Timóteo, a Filemon, nosso muito amado colaborador, 2à nossa irmã Ápia, ao nosso companheiro de armas Arquipo, e à Igreja que se reúne na tua casa. ${ }^{3}$ Graça e paz a vós, da parte de Deus nosso Pai e do Senhor Jesus Cristo. ${ }^{4}$ Dou sempre graças ao meu Deus, lembrando- me de ti em minhas orações, ${ }^{5}$ porque ouço falar do teu amor e da fé que te anima em relação ao Senhor Jesus e para com todos os santos. ${ }^{6}$ Possa a tua generosidade, inspirada pela fé tornar-se eficaz pelo conhecimento de todo bem que nos é dado realizar por Cristo. ${ }^{7}$ De fato, tive grande alegria e consolação por causa do teu amor, pois, graças a ti, irmão, foram reconfortados os corações dos santos. ${ }^{8}$ Por isso, tendo embora toda liberdade em Cristo de te ordenar o que convém, ${ }^{9}$ prefiro pedir por amor. É na qualidade de Paulo, velho e agora também prisioneiro de Cristo Jesus, ${ }^{10}$ que venho suplicar-te em favor do meu filho Onésimo, que eu gerei na prisão. ${ }^{11}$ Outrora ele te foi inútil, mas doravante será muito útil a ti, como se tornou para mim. ${ }^{12}$ Mando-o de volta a ti; ele é como se fosse meu próprio coração. ${ }^{13}$ Eu queria segurá-lo comigo para que, em teu nome, ele me servisse nesta prisão que me valeu a pregação do evangelho. ${ }^{14}$ Entretanto, nada quis fazer sem teu consentimento, para que tua boa ação não fosse como que forçada, mas espontânea. ${ }^{15}$ Talvez ele tenha sido retirado de ti por um pouco de tempo, a fim de que o recuperasses para sempre, ${ }^{16}$ não mais como escravo, mas, bem melhor do que como escravo, como um irmão amado: muitíssimo para mim e tanto mais para ti, segundo a carne e 
segundo o Senhor. ${ }^{17}$ Portanto, se me consideras teu amigo, recebe-o como se fosse a mim mesmo. ${ }^{18} \mathrm{E}$ se ele te deu algum prejuízo ou te deve alguma coisa, põe isso na minha conta. ${ }^{19} \mathrm{Eu}$, Paulo, escrevo de meu punho, eu pagarei... para não dizer que também tu és devedor de ti mesmo a mim! ${ }^{20} \mathrm{Sim}$, irmão, eu quisera mesmo abusar da tua bondade no Senhor! Dá este conforto a meu coração em Cristo. ${ }^{21}$ Eu te escrevo certo da tua obediência e sabendo que farás ainda mais do que te peço. ${ }^{22}$ Ao mesmo tempo, prepara-me também um alojamento, porque, graças às vossas orações, espero que vos serei restituído. ${ }^{23}$ Saudações de Epafras, meu companheiro de prisão em Cristo Jesus, ${ }^{24}$ de Marcos, Aristarco, Demas e Lucas, meus colaboradores. ${ }^{25}$ A graça do Senhor Jesus Cristo esteja com o vosso espírito.

Recebido em 14.08.2015 - aprovado em 25.09.2015 